\title{
Sociality of Columbian ground squirrels in relation to their seasonal energy intake
}

\author{
Mark E. Ritchie ${ }^{1, *}$ and Gary E. Belovsky ${ }^{2}$ \\ ${ }^{1}$ School of Natural Resources, University of Michigan, Ann Arbor, MI 48109, USA \\ 2 Department of Biology and School of Natural Resources University of Michigan Ann Arbor, MI 48109, USA
}

Received November 3, 1989 / Accepted February 12, 1990

\begin{abstract}
Summary. Seasonal energy intake was estimated for ten populations of Columbian ground squirrels (Spermophilus columbianus) in northwestern Montana. We calculated daily energy intake for an average ground squirrel in each population using measurements of feeding time, consumption rates of different vegetation types (monocots vs. dicots), and the proportion of monocots and dicots in the diet. These daily energy intakes were multiplied by the length of the plant growing season for each population to estimate seasonal energy intake, i.e. over the ground squirrel active season. Amicable interaction rates measured for each population varied with seasonal energy intake, but not with environmental heterogeneity, sex ratio, or the ratio of adults to juveniles. In particular, amicable interactions among adult-juvenile and juvenile-juvenile pairs increased as seasonal energy intake decreased. The proportion of females breeding as yearlings increased as seasonal energy intake increased. This suggests that "harsh" environments reduce the energy available for juvenile growth and development, leading to delayed dispersal and age at first reproduction. These responses may promote the formation of kin groups and increased amicable interactions within those groups. The length of the plant growing season may determine environmental "harshness" across elevational gradients, but at a particular elevation, "harshness" may depend on factors determining daily food intake.
\end{abstract}

Key words: Social behavior - Amicable interactions Energy intake - Ground squirrels - Plant growing season

Columbian ground squirrels (Spermophilus columbianus) inhabit a wide range of habitats which vary in the length of the plant growing season, food abundance, and eleva-

* Current address and address for offprint requests: Department of Ecology, Evolution, and Behavior, University of Minnesota, Minneapolis, MN 55455, USA tion (Shaw 1925; Moore 1937; Manville 1959; Belovsky and Ritchie 1990). A number of different mechanisms have been proposed to explain how environmental "harshness" influences ground squirrel sociality, or the rate of amicable (non-agonistic) interactions. Environmental "harshness" may affect ground squirrels' ability to prepare for hibernation (typically lasting 8-9 months) by influencing (1) the amount of time available for their growth and fat storage (length of the active season), and (2) the amount of energy available each day for conversion into growth and fat storage (daily energy intake) (Barash 1974, 1980; Hoogland 1979, 1981; Andersen et al. 1976; Webb 1980, 1981).

Barash (1974) hypothesizes that ground squirrel sociality is related to environmental "harshness" as defined by the portion of the year that squirrels can be active feeding. When maturation rate is slow, juveniles will remain near the natal burrow and delay dispersal for two reasons. (1) Greater proximity of juveniles to the natal burrow implies a greater encounter rate or opportunity for interactions among kin. These interactions are more likely to be amicable (Alexander 1974; Hamilton 1964). (2) Delayed dispersal leads to a longer period of interaction among subadults and adults. This means that interactions are among familiar individuals, and more likely to be amicable (Michener 1983, 1984). If so, the whole population will exhibit a higher amicable interaction rate and, hence, greater sociality.

Michener (1977) and Armitage (1981) suggest that amicable interaction rates change only in response to large differences in life history traits, such as age at dispersal and first reproduction. Such differences may result from large differences in energy intake between populations but may also reflect differences in body size of adults. For a given length of the growing season, juveniles that must attain a larger adult body size will disperse and reproduce at a greater age than juveniles attaining a smaller adult size (Armitage 1981).

Armitage $(1977,1982)$ suggests that sex ratio, kin relationships, and age structure, which may vary with random demographic changes (e.g. mortality, dispersal, 
Table 1. Basic population data for different ground squirrel populations, by site and year, in chronological order

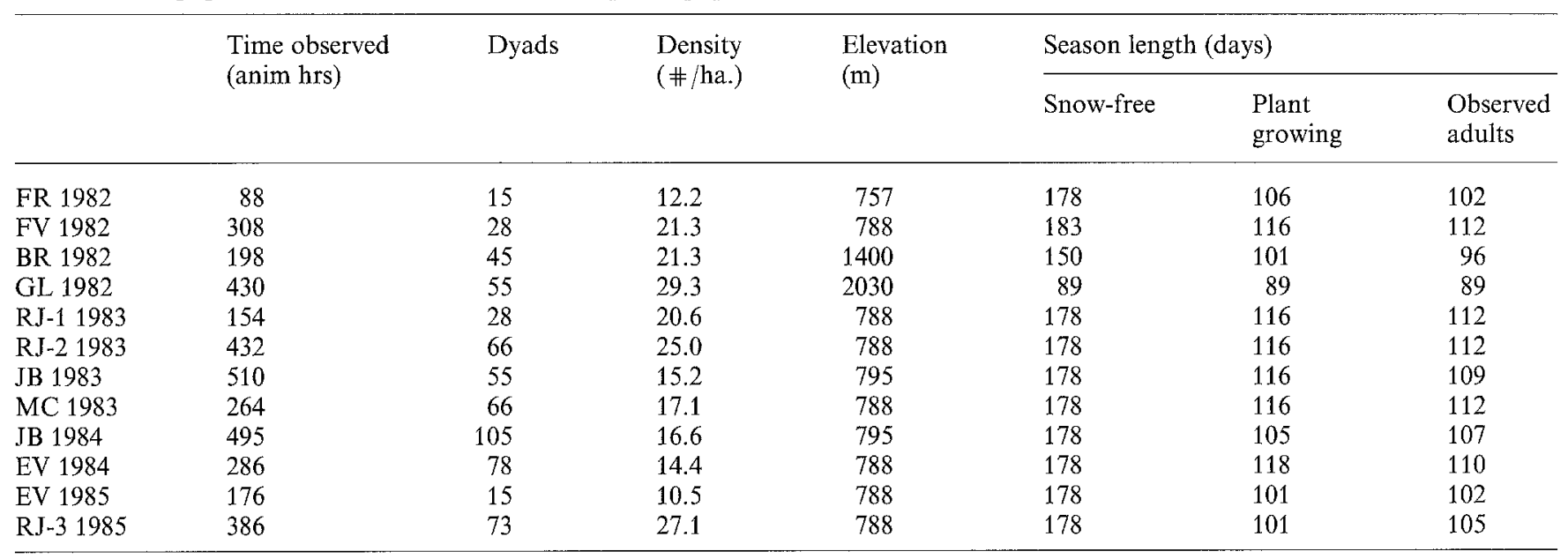

\begin{tabular}{lllll}
\hline & $\begin{array}{l}\text { Season } \\
\text { length } \\
\text { (days) } \\
\text { juv observed }\end{array}$ & $\begin{array}{l}\text { Distance } \\
\text { to nearest } \\
\text { colony } \\
\text { (km) }\end{array}$ & $\begin{array}{l}\text { Sex } \\
\text { ratio } \\
\text { (\% males) }\end{array}$ & $\begin{array}{l}\text { Adults/ } \\
\text { juv }\end{array}$ \\
\hline FR 1982 & 48 & 1.4 & - & 1.30 \\
FV 1982 & 57 & 0.4 & - & 1.00 \\
BR 1982 & 43 & 2.4 & - & 0.90 \\
GL 1982 & 37 & 1.0 & - & 1.25 \\
RJ-1 1983 & 58 & 0.2 & 33 & 1.00 \\
RJ-2 1983 & 56 & 0.2 & 40 & 0.70 \\
JB 1983 & 54 & 0.4 & 45 & 0.90 \\
MC 1983 & 56 & 1.0 & 50 & 0.40 \\
JB 1984 & 52 & 0.4 & 45 & 1.20 \\
EV 1984 & 55 & 0.5 & 60 & 0.85 \\
EV 1985 & 47 & 0.5 & 40 & 1.00 \\
RJ-3 1985 & 49 & 0.2 & 50 & 0.95 \\
\hline
\end{tabular}

and/or emigration), may determine ground squirrel sociality. This hypothesis generates a number of testable predictions. For example, populations with a high degree of relatedness among individuals or lower proportion of adults would be expected to be more social. Similarly, if a population is composed primarily of males, which are more frequently agonistic, then the population may be less social.

Finally, Webb (1981) argues that environmental heterogeneity (patchiness of suitable habitat) may influence sociality. Ground squirrel colonies typically are grassy meadows surrounded by a variety of habitat types that are unsuitable for ground squirrels, e.g., rocky outcroppings, plowed fields, dense forest, etc. Juveniles may not disperse because suitable habitat is too distant or the immediately surrounding habitat is too hostile. This delay in dispersal might increase competition for food or space with adults and other juveniles, increasing the agonistic rate and decreasing sociality.

We examine the relative importance of these mechanisms in different populations of Columbian ground squirrels. Average body mass of adults and juveniles, daily energy intake, length of the plant growing season, distance to nearest ground squirrel colony, population sex ratio, and adult: juvenile ratio were estimated for ten different Columbian ground squirrel populations. These parameters were then related to rates of amicable and agonistic interactions.

\section{Study areas}

The study was carried out at ten different locations in northwestern Montana during the summers of 19821985. Two sites, JB and EV, were sampled in two different years, providing 12 samples of social interaction rates and seasonal energy intake.

The sites ranged in elevation from $757-2030 \mathrm{~m}$. Length of the plant growing season ranged from 78-118 days and the number of snow-free days ranged from 89-183 days (Table 1). Vegetation varied significantly in total biomass and proportion (by biomass) of monocots and dicots, which differ in their food value to ground squirrels. The sites are much more fully described in Belovsky and Ritchie (1990).

\section{Methods}

The length of the active season for ground squirrels may be limited by two possible factors that potentially control the onset and termination of estivation or hibernation: (1) progressive desiccation of vegetation over the summer and/or (2) the covering of vegetation by snow (Bintz 1984; Hudson and Deavers 1973). Consequently, season length was calculated in two ways: (1) plant growing season, the number of days from complete snow-melt until plant biomass began to decline, and (2) snow-free days, the number of days from complete snow-melt until the first snowfall of greater than one inch in the fall.

Plant biomass was measured by clipping, drying and weighing all live, above-ground vegetation in each of ten $0.1 \mathrm{~m}^{2}$ plots set $5 \mathrm{~m}$ apart in a transect across each colony (Belovsky and Ritchie 1990). The time at which biomass began to decline was determined by clipping vegetation in a new transect every 5 days through June and July (except at GL, the high elevation site, where snowfall terminated the plant growing season). The length of the plant growing season for sites at the same elevation varied due to differences in aspect to the sun, intensity of cattle grazing, and irrigation schedules of nearby fields. 
Observed length of the active season for ground squirrels was measured as the time from date of first emergence to last immergence for any ground squirrel in the population or age class. Season lengths were recorded for both adults and juveniles.

Plant growing season (Table 1) is a better estimate of the length of the active season for ground squirrels than snow-free days, since the number of snow-free days may include the late summer period in which vegetation is no longer digestible or succulent enough for ground squirrel survival (Belovsky and Ritchie 1990; Webb 1980; Hudson 1962; Davis 1976; Blake 1972; Bintz 1984). Plant growing season correlated very well with the observed length of the active season for adults $\left(r^{2}=0.91, N=12, P<0.001\right)$.

Demography. At six study sites (RJ-1, RJ-2, RJ-3, JB, MC, and $\mathrm{EV})$, ground squirrels were live-trapped with Tomahawk wire cage traps. Each captured squirrel was sexed, weighed, and checked for reproductive condition. Each squirrel was also individually marked with a numbered metal ear tag and colored strips of SafeFlag material looped through the ear tag and stapled; in this way, individuals could be identified at distances greater than $100 \mathrm{~m}$. Feces deposited in the trap or at burrow entrances were collected for diet analysis (Ritchie 1988; Belovsky and Ritchie 1990). Trapping was conducted before and just after weaning so that litter mates and mother-offspring pairs could be determined (Murie and Harris 1978, 1984; Michener 1980a; Dobson and Kjelgaard 1985).

During foraging behavior observations (see below), the density of squirrels at each site and year was measured as the maximum number of squirrels seen during any half-hour interval divided by the area containing the home burrows of the individuals observed. This measure was corroborated at sites where individuals were marked, since marked individuals comprised at least $90 \%$ of the population. The ratio of adults to juveniles was determined from the number of adults and juveniles comprising the maximum number of squirrels seen during any half-hour.

Feeding. Average daily energy intake (I) was calculated for average individuals, adults, and juveniles at each site according to the following formula:

$I=\frac{T}{\left[c_{m} p+c_{d}(1-p)\right]}\left[e_{m} p+e_{d}(1-p)\right]$

where $T$ is average daily feeding time, $p$ is the proportion of monocots in the observed diet, $c_{m}, c_{d}$ are the average times necessary to consume $1 \mathrm{~g}$ (dry mass) of monocots and dicots, respectively, and $e_{\mathrm{m}}, e_{\mathrm{d}}$ are the average digestible energy contents (per g dry mass) of monocots and dicots, respectively. The methods of measuring all these parameters are reported in detail in Belovsky and Ritchie (1990) and Ritchie (1988). The measurements were made 7-14 days after juveniles were weaned at each site.

Daily feeding time was estimated from scans of the colony every half-hour during the day. The proportion of individuals observed each half-hour during the day relative to the maximum number of individuals observed any half-hour was assumed to represent the proportion of the half-hour spent feeding by an average squirrel. The sum of these proportions over the entire day provided an estimate of average daily feeding time.

Consumption rates of monocots and dicots at a site were calculated by measuring (1) the average number of bites of each food type taken by individuals in a two-minute period and (2) the average mass per bite for each food type. Mass per bite was measured by collecting and weighing portions of uneaten plants that correspond to plant parts observed to be eaten by ground squirrels. Biting rate and mass per bite were then multiplied to obtain consumption rates $(\mathrm{g} / \mathrm{min}$ ) for each food type. The inverse of consumption rate $(\mathrm{min} / \mathrm{g})$ was used to estimate cropping time.

The observed average proportion of monocots vs. dicots in ground squirrel diets at a site was measured by analyzing feces using microhistological techniques (Ritchie 1988; Belovsky and Ritchie 1990). Digestible energy content of monocots and dicots at each site were determined by in vivo feeding trials in which fresh vegetation from each site was presented to squirrels (Belovsky and Ritchie 1990).

Seasonal energy intake was calculated by multiplying average daily energy intake by the observed length of the active season (Table 1). A separate calculation was made for adults, juveniles, and all individuals combined at each site. Seasonal energy intake, therefore, is a crude calculation of the total energy accumulation by an individual during the active season.

Estimates of daily energy intake at intervals throughout the active season were not made. It is possible that populations with low daily energy intake during one part of the active season might compensate with a higher energy intake at another time. This seems unlikely, however, given the absence of major differences between the sites in the seasonal thermal changes and phenology of vegetation (Belovsky and Ritchie 1990). Therefore, we are confident that our measure of seasonal energy intake is adequate.

Social behavior was observed simultaneously with foraging measurements at each site (7-14 days after weaning). Observing during this period reduces the potential for error in comparing sociality and feeding, due to potential seasonal variation in social interaction rates (Dobson 1983; Michener 1983; Betts 1976) and feeding. Social interactions were recorded during 5 min scans of the colony performed every $15 \mathrm{~min}$ and focal observations of individuals. Interaction rates were expressed relative to the number of dyads (potentially interacting pairs) in a population (Michener 1980 b). The number of dyads in a population (D) can be computed as

$$
D=\sum_{j=1}^{N} N-j,
$$

where $N$ is the number of squirrels in the population or age class. Dyadic interaction rates provide the most accurate assessment of the propensity for social interaction within a population (Michener 1980 b). Dyadic interaction rates factor out population size but not density as a potential factor affecting sociality, since a given number of dyads may be closely or widely distributed in space.

Social interactions were classified by the age class of participants: adult-adult, adult-juvenile, or juvenile-juvenile, when sample sizes were sufficiently large ( $\geq 5$ dyads in each category). For populations with marked individuals, interactions were also classified as being between siblings, non-siblings, mothers, or strange adults.

Interactions were defined using Betts' (1976) ethogram for Columbian ground squirrels. An interaction was considered agonistic if an individual was displaced by another. Amicable interactions were allo-grooming (grooming of one individual by another), kissing (rubbing noses), playing, or visually interacting without displacement. Since interaction rates in different populations were made by the same observers, subjective classifications of behavior were comparable; however, our interaction rates may not be comparable to those recorded by other researchers (McLean 1984; Davis 1984).

\section{Results}

Sociality, life history traits, and energy intake

The feeding parameters measured at each site are presented in Table 2 and were used to compute daily and seasonal energy intake (daily energy intake $x$ season length).

The overall rate of amicable interactions increased significantly as calculated seasonal energy intake decreased (Fig. 1 a) $(r=-0.87, N=12, P=0.003)$. Agonistic interactions, however, did not change significantly with seasonal energy intake (Fig. $1 \mathrm{~b})(r=0.01, P=$ 0.998 ). This increase in sociality is entirely due to energy consumption by juveniles, because overall amicable in- 
Table 2. Parameters for calculating daily energy intake at each site. Sample sizes are shown in parentheses

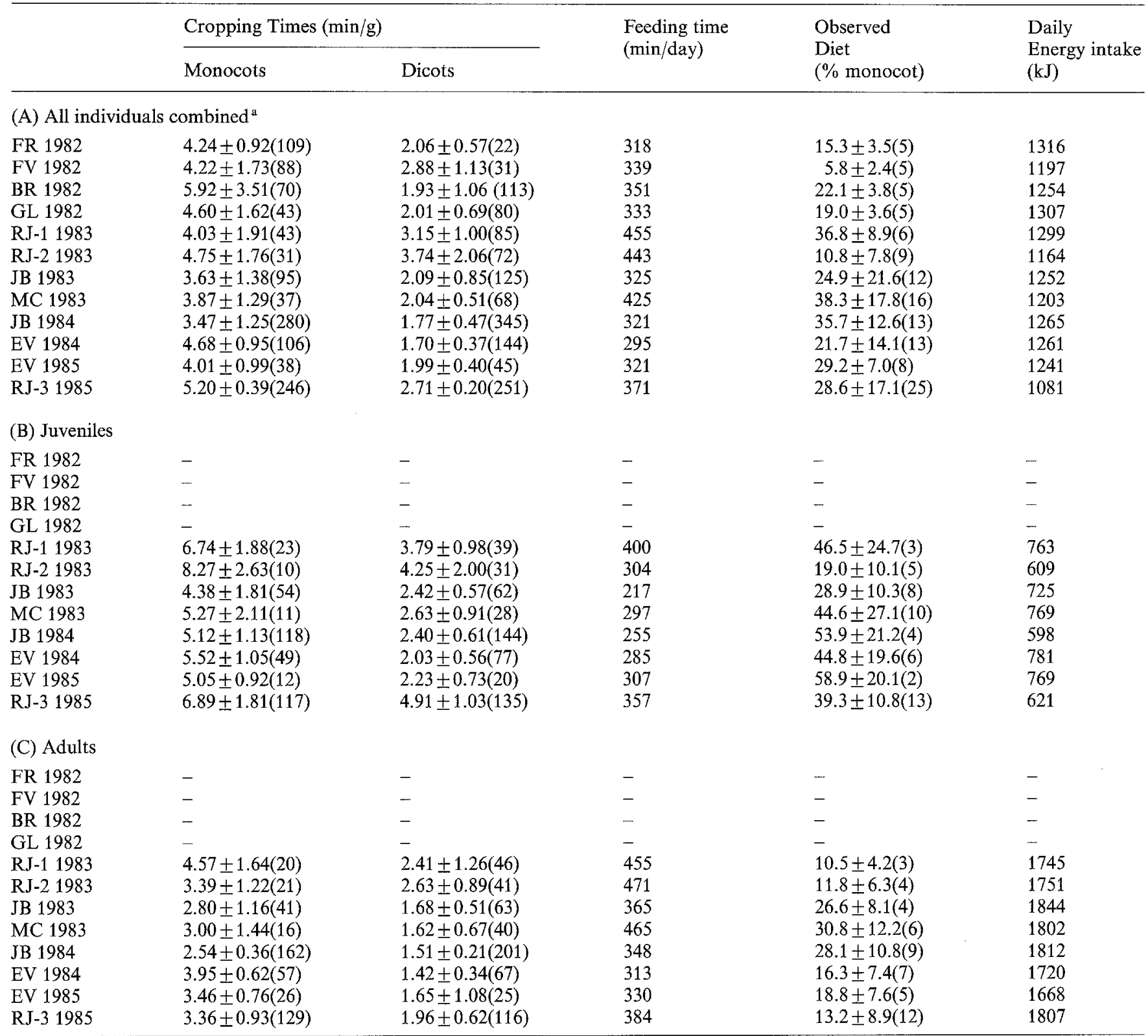

${ }^{a}$ Data from Belovsky and Ritchie (1990)

b Digestible energy content values were $9.44 \mathrm{~kJ} / \mathrm{g}$ for monocots and $10.2 \mathrm{~kJ} / \mathrm{g}$ for dicots at all sites and for all individuals (Belovsky and Ritchie 1990)

teraction rates increased as juvenile seasonal energy intake decreased $(r=-0.77, N=8, P=0.023)$ but showed no relationship with adult seasonal energy intake $(r=$ $0.10, P=0.81$ ).

Amicable and agonistic interaction rates within particular age classes of dyads also changed with seasonal energy intake. From a correlation analysis of the amicable and agonistic interaction rates for the different age classes of dyads against several independent variables (Table 3), the following patterns emerged: (1) Amicable interactions among juvenile-juvenile (J-J), and adult-juvenile (A-J) dyads increased as overall seasonal energy intake declined. (2) Agonistic interactions among $\mathrm{J}-\mathrm{J}$ and A-J dyads also increased as seasonal energy intake decreased. (3) No relationships were found for adult-adult (A-A) interactions.

Seasonal energy intake is the product of season length and daily energy intake. Consequently, the importance of each of these factors on interaction rates can be examined with multiple linear regression if the two variables are log-transformed. Together, these two variables explained $82.7 \%(P<0.001)$ of the variance in amicable interactions, $62.3 \%$ by season length and $20.4 \%$ by daily energy intake. Both independent variables were 


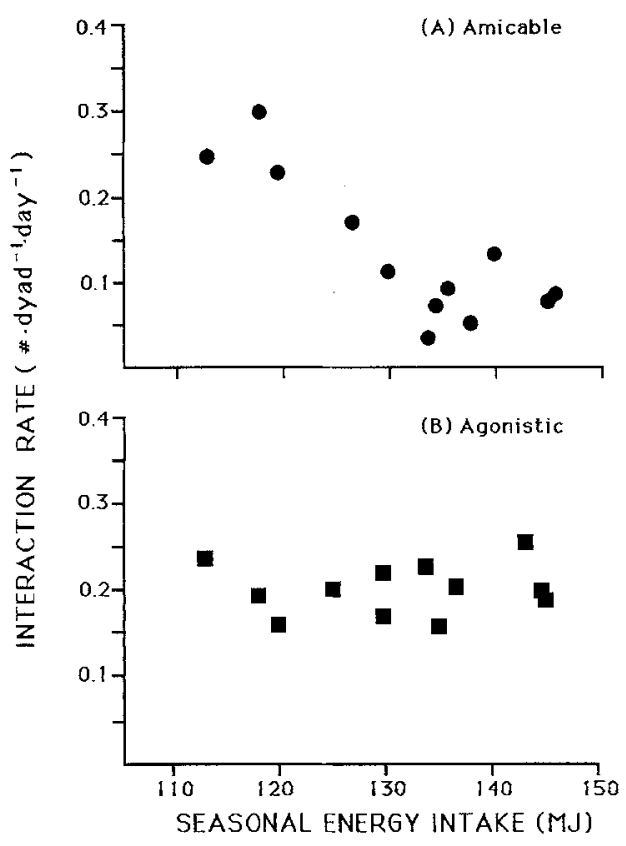

Fig. 1 A, B. The relationship between $(\mathbf{A})$ amicable interaction rate and seasonal energy intake $(r=-0.87, N=12, P=0.003)$, and (B) agonistic interaction rate and seasonal energy intake $(r=-0.01$, $P=0.998)$

significant (season length: $r_{p}=-0.89, d f=8, P=0.006$; daily energy intake: $r_{p}=-0.45, P=0.07$ ).

At least three life history traits were also associated with seasonal energy intake. The proportion of yearling females that produced litters (a measure of age at first reproduction) increased significantly with seasonal energy intake (Fig. 2) $(r=0.95, N=4, P<0.05)$. In addition, average litter size at weaning increased as seasonal energy intake increased $(r=0.85, N=8, P<0.01)$. Litter mass at weaning did not vary significantly across sites $(F=$ $0.56, d f=7,74, P>0.20$ ). However, average body mass of individual juveniles at 7-14 days after weaning increased with seasonal energy intake $(r=0.85, P=0.02)$.
Adult mass did not correlate significantly with seasonal energy intake $(r=0.01, N=8, P=0.96)$. Small juveniles at a site also implied that juveniles were smaller relative to adults, since adult mass/juvenile mass increased as seasonal energy intake decreased $(r=0.72, P=0.04)$.

\section{Demographic patterns}

Amicable interactions appeared to occur primarily among kin (Fig. 3). Amicable J-J interactions mostly occurred between siblings $(t=4.04, d f=16, P<0.001$ ), while agonistic interactions occurred primarily between non-siblings $(t=4.32, P<0.001)$. A similar pattern was observed for A-J interactions, since amicable interactions primarily occurred between mother and offspring $(t=4.55, P<0.001)$, but agonistic interactions occurred mostly between strange adults and juveniles $(t=4.12$, $P<0.001$ ). Since none of the sites was observed for more than two years and paternity was unknown, we could not examine the relationship between sociality and kin structure in detail.

Social interaction rates showed little relationship to other demographic variables and/or environmental heterogeneity. Amicable interaction rates were not correlated with either the ratio of adults to juveniles $(r=-0.24$, $N=12, P=0.51)$ or the population sex ratio $(r=-0.09$, $N=8, P=0.75$ ). However, agonistic interaction rates exhibited a marginally significant decline with increased adult: juvenile ratio $(r=-0.51, N=12, P=0.09)$. Likewise, amicable and agonistic interaction rates showed no relationship with distance to the nearest ground squirrel colony, Webb's (1981) measure of colony isolation (amicable: $r=-0.18, N=12, P=0.60$; agonistic: $r=-0.33, P=0.30$ ).

If dispersal is delayed and juveniles stay in greater proximity to the natal burrow, population density and encounter rates should increase. One measure of both density and the potential for encounter is dyads per unit area, or dyad density. Amicable interactions increased

Table 3. Matrix of correlation coefficients of amicable and agonistic interaction rates in dyads of different age classes [Juvenile-Juvenile (J-J), Adult-Juvenile (A-J), and Adult-Adult (A-A)] against three different measures of seasonal energy intake, dyad density, and juvenile body mass. Significant coefficients are underlined

\begin{tabular}{|c|c|c|c|c|c|c|}
\hline & \multicolumn{6}{|c|}{ Interaction type } \\
\hline & \multicolumn{2}{|l|}{$\mathrm{J}-\mathrm{J}$} & \multicolumn{2}{|l|}{ A-J } & \multicolumn{2}{|l|}{ A-A } \\
\hline & Amic & Agon & Amic & Agon & Amic & Agon \\
\hline $\begin{array}{l}\text { Overall seasonal } \\
\text { energy intake }\end{array}$ & $-\underline{0.878}$ & $-\underline{0.664}$ & $-\underline{0.814}$ & -0.600 & -0.465 & -0.367 \\
\hline $\begin{array}{l}\text { Adult seasonal } \\
\text { energy intake }\end{array}$ & -0.022 & -0.509 & -0.589 & $-\underline{0.750}$ & -0.129 & 0.017 \\
\hline $\begin{array}{l}\text { Juvenile seasonal } \\
\text { energy intake }\end{array}$ & -0.632 & $-\underline{0.876}$ & -0.690 & -0.498 & -0.489 & -0.466 \\
\hline Dyad density & $\underline{0.776}$ & $\underline{0.772}$ & 0.888 & 0.320 & 0.441 & 0.591 \\
\hline Juvenile mass & -0.562 & -0.605 & -0.814 & -0.597 & 0.049 & -0.784 \\
\hline
\end{tabular}



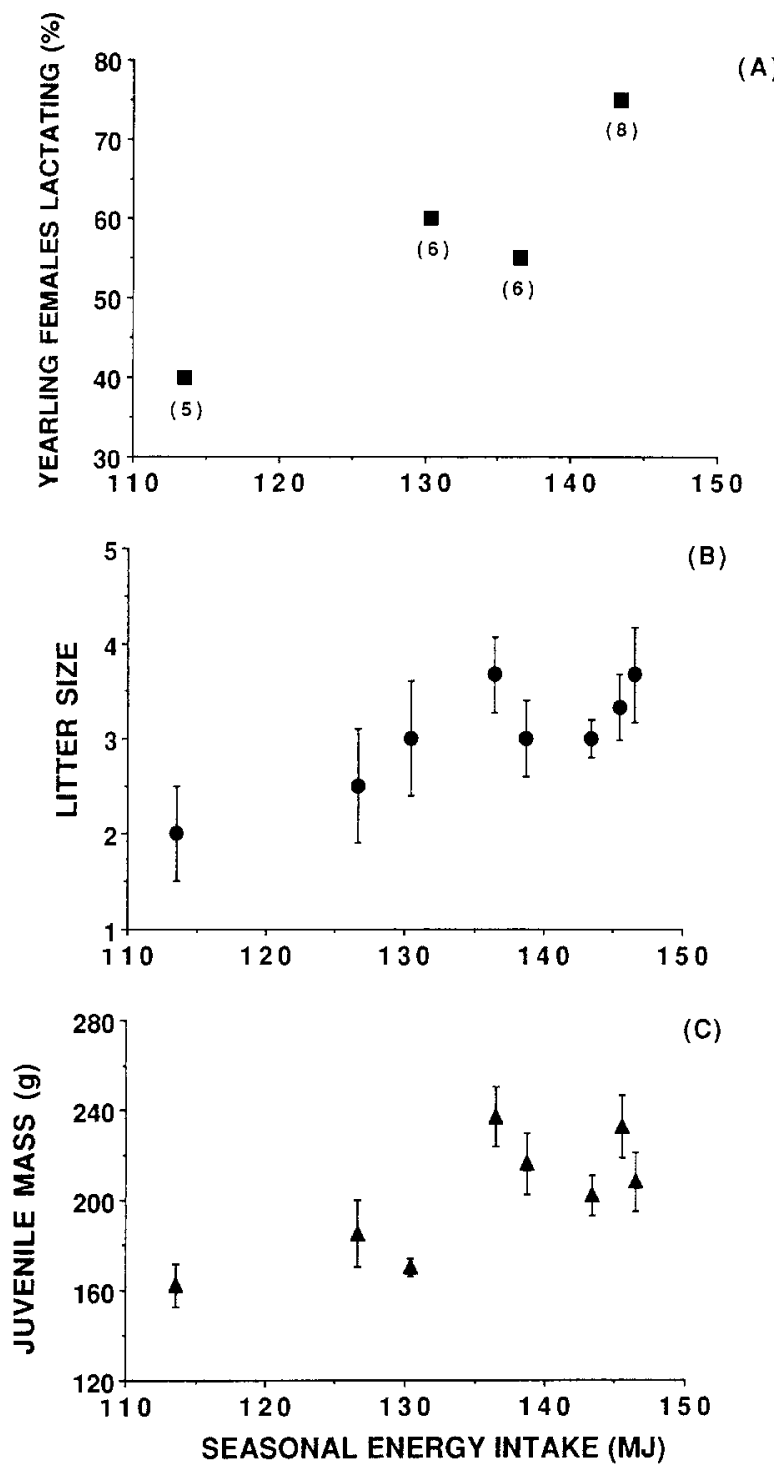

Fig. 2 A-C. The relationship between three life history variables and seasonal energy intake. In (A), the proportion of yearlings breeding is presented for four sites (RJ-3 1985, RJ-2 1983, and JB 1983 and 1984), along with the number of yearling females (in parentheses) $(r=0.95, N=4, P<0.10)$. In (B), the average litter size ( \pm S.D.) is presented for eight sites where individuals were marked $(r=0.85, N=8, P=0.02)$. In $(\mathbf{C})$, the average mass of juveniles 7-14 days after weaning ( \pm S.E.) is presented for these same eight sites $(r=0.85, P=0.02)$

significantly with dyad density $(r=0.62, N=12, P=$ $0.05)$, but agonistic interactions did not $(r=0.10, P=$ 0.79 ). In addition, amicable interactions among $\mathrm{J}-\mathrm{J}$ and A-J dyads increased with dyad density (Table 3 ).

In our populations, overall seasonal energy intake is negatively correlated with dyad density $(r=-0.58$, $N=12, P=0.04$ ) and juvenile mass after weaning (see above), as expected if food limits density. We used a multiple linear regression to separate the effects of these three factors on interaction rates. For overall amicable interactions, only seasonal energy intake was significant when all three variables were included, and it explained $72 \%$ of the variance in amicable interaction rate $(P=$

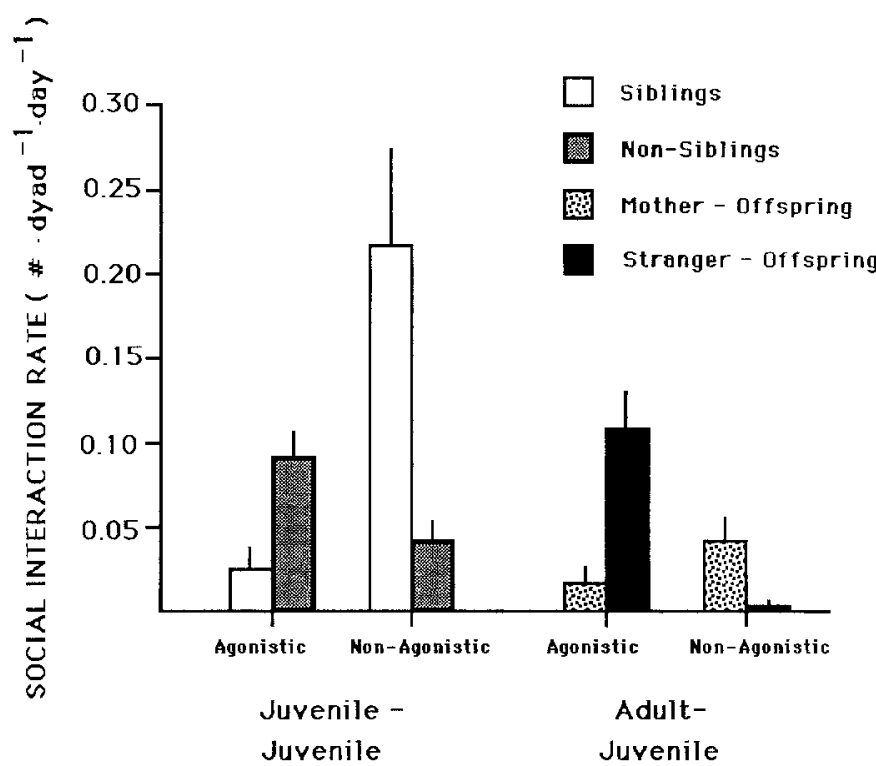

Fig. 3. Mean interaction rates ( $t$ S.E.) for two types of ground squirrel dyads, juvenile-juvenile (J-J) and adult-juvenile (A-J). For $J$-J dyads, both amicable and agonistic interaction rates are compared between dyads involving siblings (open bars) and non-siblings (shaded bars). For A-J interactions, agonistic and amicable interaction rates are compared between dyads involving mother and offspring (dotted bars) and strangers and offspring (solid bars)

$0.04, d f=5)$. Due to small sample sizes $(N=6$ in some cases), analyses by age category were not conducted.

\section{Discussion}

\section{Competing hypotheses}

Environmental "harshness". Barash (1974) considers the length of the active season for ground squirrels to be set by the time vegetation is not covered by snow, with "harshness" increasing as this period declines. However, this definition may not be appropriate at lower elevations, where the ground squirrels' active season may be limited by declining or drying vegetation (Belovsky and Ritchie 1990; Hudson 1962; Blake 1972; Davis 1976; Bintz 1984). Furthermore, Webb (1980) argues that a long foraging season does not necessarily indicate a less "harsh" environment, since average daily feeding time can affect the total time ground squirrels have to forage over the active season. These arguments are not all inclusive, however, because sites with abundant food may provide more energy per unit time and ground squirrels could potentially compensate for a shorter active season with greater energy returns each day. Our seasonal energy intake parameter (daily energy intake $x$ length of the plant growing season) combines all of these important aspects of harshness.

Using seasonal energy intake as a reflection of "harshness", the hypothesis that ground squirrel sociality increases with environmental "harshness" is clearly supported (Figs. 1, 2). In particular, increased sociality in this study results from higher rates of amicable inter- 
action among siblings and mother-offspring pairs, exactly as Barash (1974) predicts. Furthermore, "harsh" environments lead to a lower proportion of yearlings reproducing, smaller litters, and smaller juveniles relative to adults (Fig. 2), as predicted by Armitage (1981) and Michener (1977).

Demographic variation. Armitage (1977) argues that variation in sociality among marmot populations might result from random demographic variation. Random mortality, reproduction, emigration, and dispersal of individuals in relatively small ( $<25$ inds) populations could result in large differences among populations in age structure, sex ratio, and kin structure. Accordingly, amicable interactions would be most likely in populations composed of kin and a high proportion of subadults and/or females. Our data do not support this hypothesis; we found only a weak correlation between increased agonistic interactions and increased proportion of adults. Our data represent a fairly weak test of this hypothesis, however, because we could not measure details of kin structure in most populations, thereby reducing our sample size.

Environmental heterogeneity. Webb (1981) found that agonistic interactions in yellow-bellied marmots (Marmota flaviventris) increased as colonies became more isolated, i.e., farther from suitable marmot habitat. We did not find this relationship in our study, perhaps for two reasons. First, our colonies were generally isolated by cultivated fields and roads, which may be less of a barrier than the talus slopes, rock cliffs, and dense forest in Webb's (1981) study. Second, agonistic interaction rates are probably not a sufficient description of sociality (Armitage 1981; Dobson 1983; Barash 1974); in our study, agonistic interactions show much less variation than amicable interactions.

\section{Factors affecting sociality}

Our results suggest that both daily energy intake and length of the growing season define environmental "harshness" and independently determine sociality. Other workers (Webb 1980; Hoogland 1979, 1981; Armitage 1981) have also argued this point. In our study, differences among colonies in daily energy intake are due to variation in the thermal environment, as it affects daily feeding time (Belovsky and Slade 1986; Belovsky and Ritchie 1990) and vegetation abundance and quality, as they affect cropping rate of plant food (Belovsky and Ritchie 1990).

The length of the active season for ground squirrels, based on plant growing season, is important in this study when comparisons are made across an elevational gradient. If comparisons are made between populations with similar plant growing seasons but different food abundances or daily feeding times, daily energy intake is more important. For example, at two colonies with very similar plant growing seasons and elevations (EV 1985 and RJ-3 1985), ground squirrels at RJ-3 consumed
$160 \mathrm{~kJ}$ less energy per day than those at EV, but exhibited more than twice the rate of amicable interactions.

Why should energy intake be so important to ground squirrel sociality? Due to the relatively short length of the active season, ground squirrels have a limited time to obtain sufficient energy to reproduce and store fat for hibernation. Small differences in daily energy intake by individuals can lead to large differences in their growth rate, reproduction, and preparation for hibernation (Ritchie 1990). Consequently, differences in energy intake may affect the life history and dispersal patterns of juveniles, which in turn may affect social interaction rates.

\section{Is sociality adaptive?}

While our study was designed to test what proximate factors (e.g. "harshness") might lead to variation in sociality, several points about the ultimate adaptive value can be made. Increased amicable interactions could not be explained as arising from more frequent encounters among kin or population members as density increases. Instead, amicable interactions occurred more frequently than expected by random encounter, suggesting some potential adaptive value for sociality.

If energy intake is important to survival and reproduction, sociality might not be adaptive if it reduces feeding time or cropping rates of food. This is especially true since sociality increases as daily energy intake decreases. However, we found no correlation between sociality and cropping rate $(r=0.17, N=12, P=0.53)$ or feeding time $(r=-0.24, P=0.33)$. These results suggest that observed levels of sociality may not cost much in terms of energy intake, perhaps because time spent in social interactions is a very small part of the total time budget. However, these data do not indicate whether social interactions are energetically more costly than other behaviors.

If sociality increases independently of density and is not costly to energy intake, why should it be favored in "harsher" environments? Our study provides less insight on this question, but we suggest some possibilities.

First, as seasonal energy intake decreases, individuals might expand their home ranges to try to increase their daily energy intake, thereby increasing the potential for intrusion by other population members. Intrusion on an individual's home range should reduce food abundance and energy intake by the resident, and consequently fitness. If the intruder was kin, however, inclusive fitness might increase. Therefore, as home range areas and intrusion rates increase in response to decreasing energy intake, enhancing the proximity of kin through amicable interactions may tend to make intruders be kin.

A second possibility is that related individuals sharing their home range may also share in the defense of that area, reducing the time and energy cost of chasing intruders. Sharing the costs of chasing intruders may become beneficial as intrusion rates increase in response to lower seasonal energy intake. Coalitions of kin appear 
to serve a similar function in other social mammals (Dunbar 1984; Silk 1982; Lamprecht 1978) as well as other ground squirrel species (Hoogland 1981; McLean 1984).

Increased social interactions might also further reduce predation risk and the time spent watching for and hiding from predators (Hoogland 1981, 1983; Alexander 1974). As a result, individuals facing an energy shortage in "harsh" environments may increase amicable interactions to share the time cost of vigilance and thereby improve their food intake rate.

\section{Conclusion}

Our study supports Barash's (1974) original idea that sociality of ground squirrels increases with environmental "harshness", as defined by seasonal energy intake. As seasonal energy intake decreases, juveniles reach adult size more slowly and subadults delay reproduction. Consequently, juveniles and subadults may remain near their natal burrow, increasing encounters among kin. However, increased amicable interactions are not explained solely by increased encounters among kin; when kin interact, they are more likely to be amicable in "harsh" environments. This study does not support the idea that variation in sociality is determined by either random demographic variation among populations (Armitage 1977, 1982) or degree of colony isolation (Webb 1981). Therefore, we suggest that the social behavior of animals may be linked to their ability to acquire energy or nutrients.

Acknowledgements. We thank T.H. Clutton-Brock, B.S. Low, O.J. Schmitz, J.B. Slade, and two anonymous reviewers for reading various drafts of the manuscript. We also thank R. Henderson, D. McCullough, J.B. Slade, and S. Wall for help in collecting the data. Finally, we thank the personnel at the National Bison Range and Glacier National Park for their help, and landowners J. Brady, L. Evans, R. Jensen, and R. McDaniels for access to their land. This study was supported by NSF grants BSR-8307352 to G.E. Belovsky and BSR-8501040 to the authors, and Grants-in-Aid from Sigma Xi, the Scientific Research Society, to M.E. Ritchie.

\section{References}

Alexander RD (1974) The evolution of social behavior. Ann Rev Ecol Syst 5:325-383

Andersen DC, Armitage KB, Hoffman RS (1976) Socioecology of marmots: female reproductive strategies. Ecology 57:552560

Armitage KB (1977) Social variety in the yellow-bellied marmot: a population - behavioral system. Anim Behav 25:585-593

Armitage KB (1981) Sociality as a life-history tactic of ground squirrels. Oecologia $48: 36-49$

Armitage KB (1982) Social dynamics of juvenile marmots: role of kinship and individual variability. Behav Ecol Sociobiol $11: 33-36$

Barash DP (1974) The evolution of marmot societies: a general theory. Science 185:415-420

Barash DP (1980) The influence of reproductive status on foraging by hoary marmots (Marmota caligata). Behav Ecol Sociobiol $7: 201-205$
Belovsky GE, Slade JB (1986) Time budgets of grassland herbivores: body size similarities. Oecologia 70:53-62

Belovsky GE, Ritchie ME (1990) Geographical and seasonal variation in ground squirrel foraging. Oecologia in press

Betts BJ (1976) Behavior in a population of Columbian ground squirrels (Spermophilus columbianus). Anim Behav 24:652-680

Bintz GL (1984) Water balance, water stress, and the evolution of seasonal torpor in ground-dwelling sciurids. pp 142-166 In: The biology of ground-dwelling squirrels: annual cycles, behavioral ecology, and sociality. Murie JO, Michener GR (eds) Univ Nebraska Press, Lincoln

Blake BH (1972) The annual cycle and fat storage in two populations of golden-mantled ground squirrels. J Mammal 53:157 167

Davis DE (1976) Hibernation and circannual rhythms of food consumption in marmots and ground squirrels. Q Rev Biol $51: 477-$ 514

Davis LS (1984) Behavioral interactions of Richardson's ground squirrels: asymmetries based on kinship. pp 424-444 In: The biology of ground-dwelling squirrels: annual cycles, behavioral ecology, and sociality. Murie JO, Michener GR (eds) Univ Nebraska Press, Lincoln

Dobson FS (1983) Agonism and territoriality in the California ground squirrel. J Mammal 64:218-225

Dobson FS, Kjelgaard JD (1985) The influence of food resources on life history in Columbian ground squirrels. Can J Zool $63: 2105-2109$

Dunbar RIM (1984) Reproductive decisions: an economic analysis of gelada baboon social strategies. Princeton Univ Press, Princeton, New Jersey

Hamilton WD (1964) The evolution of social behavior. J Theor Biol 7:1-52

Hoogland JL (1979) Aggression, ectoparasitism, and other possible costs of prairie dog (Sciuridae: Cynomys spp.) coloniality. Behaviour 69:1-35

Hoogland JL (1981) The evolution of coloniality in white-tailed and black-tailed prairie dogs (Sciuridae: Cynomys leucurus and C. ludovicianus). Ecology 62:252-272

Hoogland JL (1983) Nepotism and alarm-calling in the black-tailed prairie dog (Cynomys ludovicianus). Anim Behav 31:472-479

Hudson JW (1962) Role of water in the biology of the Antelope ground squirrel. Univ Calif Publ Zool 64:1-56

Hudson JW, Deavers DR (1973) Metabolism, pulmo-cutaneous water loss and respiration of eight species of ground squirrels from different environments. Comp Biochem Physiol A 45:69100

Lamprecht J (1978) The relationship between food competition and foraging group size in some larger carnivores. Z Tierpsychol 46:337-343

Manville RH (1959) The Columbian ground squirrel in northwestern Montana. J Mammal 40:26-45

McLean IG (1984) Spacing behavior and aggression in female ground squirrels. pp 321-335 In: The biology of ground-dwelling squirrels: annual cycles, behavioral ecology, and sociality. Murie JO, Michener GR (eds) Univ Nebraska Press, Lincoln

Michener GR (1977) Effect of climatic conditions on the annual activity and hibernation cycle of Richardson's ground squirrels and Columbian ground squirrels. Can J Zool 55:693-703

Michener GR (1980a) Differential reproduction among female Richardson's ground squirrels and its relation to sex ratio. Behav Ecol Sociobiol 7:173-178

Michener GR (1980b) The measurement and interpretation of interaction rates: an example with adult Richardson's ground squirrels. Biology of Behavior 5:371-384

Michener GR (1983) Kin identification, matriarchies, and the evolution of sociality in ground-dwelling sciurids. pp 528-572 In: Recent advances in the study of mammalian behavior. Eisenberg JF, Kleiman DG (eds) Spec Publ Amer Soc Mamm 7:153

Michener GR (1984) Age, sex, and species differences in the annual cycles of ground-dwelling sciurids: implications for sociality. 
pp 79-107 In: The biology of ground-dwelling squirrels: annual cycles, behavioral ecology, and sociality. Murie JO, Michener GR (eds) Univ Nebraska Press, Lincoln

Moore AW (1937) Some effects of altitude and latitude on the Columbian ground squirrel. J Mammal 18:368-369

Murie JO, Harris MA (1978) Territoriality and dominance in male Columbian ground squirrels (Spermophilus columbianus). Can J Zool 56:2402-2412

Murie JO, Harris MA (1984) The history of individuals in a population of Columbian ground squirrels: source, settlement, and site attachment. pp 353-374 In: The biology of ground-dwelling squirrels : annual cycles, behavioral ecology, and sociality. Murie JO, Michener GR (eds) Univ Nebraska Press, Lincoln

Ritchie ME (1988) Individual variation in the ability of Columbian ground squirrels to selecti an optimal diet. Evol Ecol 2:232252

Ritchie ME (1990) Optimal foraging and fitness in Columbian ground squirrels. Oecologia 82:56-67

Shaw WT (1925) The food of ground squirrels. Am Nat 59:250264

Silk JB (1982) Altruism among female Macaca radiata: explanations of patterns of grooming and coalition formation. Behaviour $79 ; 162-188$

Webb DR (1980) Environmental harshness, heat stress, and Marmota flaviventris. Oecologia 44:390-395

Webb DR (1981) Macro-habitat patch structure, environmental harshness, and Marmota flaviventris. Behav Ecol Sociobiol $8: 175-182$ 